\title{
Equality as a Global Goal
}

\author{
Edward Anderson ${ }^{*}$
}

The Millennium Development Goals (MDGs) were established following the UN Millennium Declaration, which was approved by the UN General Assembly in September 2000. Described by some as the "world's biggest promise," they set out a series of time-bound targets to be achieved by the international community by 2015 , including a halving of extreme poverty, a two-thirds reduction in child mortality, a three-quarter reduction in maternal mortality, and universal primary education. The MDGs were, however, often criticized for having a "blind spot" with regard to inequality and social injustice. ${ }^{2}$ Worse, they may even have contributed to entrenched inequalities through perverse incentives. As some have argued, in order to achieve progress toward the MDG targets at the national level, governments focused their attention on the "easy to reach" populations and ignored more marginalized, vulnerable groups. ${ }^{3}$ The aim of this essay is examine the extent to which this widespread criticism has been successfully addressed in the Sustainable Development Goals (SDGs), approved by the UN General Assembly in September 2015.

All of the main proposals for the post-2015 development framework tried to correct this perceived blind spot in the MDGs with respect to inequality. First, there was greater emphasis on "universal" or "zero-based" targets, which specify a target of zero for negative outcomes (for example, the eradication of income poverty) or 100 percent for positive outcomes (for example, universal access to education). The report of the High-Level Panel on the Post-2015 Development Agenda proposed targets for eradicating \$1-a-day poverty; for universal

\footnotetext{
${ }^{*}$ This essay draws on a background paper by the author commissioned by the Office of the United Nations High Commissioner for Human Rights (OHCHR), "Inequality Measurement and Options for the Post-2015 Development Agenda." The arguments, interpretations, and conclusions expressed here are those of the author and do not necessarily reflect the policies or views of OHCHR.
} 
achievement of minimum learning standards; and for universal access to lower secondary education, food, and drinking water, among other necessities. ${ }^{4}$ The important thing about universal or zero-based targets is that they can only be met at the national level if they are met by all groups within the population - thus offsetting the perverse incentives problem. If met, they would also ensure a certain degree of "substantive" equality, at least in terms of people's access to basic goods and services.

Second, greater emphasis was placed on the disaggregation of targets and indicators. Although the documentation for the MDGs clearly states that indicators needed to be disaggregated by gender and between rural and urban areas, most post-2015 proposals called for more extensive disaggregation, including by income group, geographical location, age, and disability status, as well as by gender and rural/urban location. ${ }^{5}$ This would allow persistent inequalities in outcomes such as health status or educational attainment, which reflect past or ongoing discrimination, to be detected and addressed. It was also argued that disaggregating indicators alone is not enough; targets also need to be disaggregated in some way, particularly those that do not necessarily have to be met by all groups within the population. For example, the report of the UN Sustainable Development Solutions Network argued that its proposed targets for reducing child and maternal mortality should be met for "every subpopulation," and not just at the national level. ${ }^{6}$

Fourth, there were proposed targets for reducing income inequality. This included calls for a target for reducing income inequality within countries, measured for example by the Gini coefficient or the Palma index. ${ }^{7}$ The Gini coefficient is a widely used measure of income inequality that varies between 0 (indicating perfect equality) and 1 (indicating perfect inequality). The Palma index is another measure of income inequality, equal to the ratio of the share of national income received by the richest 10 percent of the population to the share received by the poorest 40 percent of the population. There were also some calls for a target 
for reducing international income inequality, although the only concrete proposal was that the global Palma income inequality index should be reduced by 25 percent. ${ }^{8}$ These proposals, however, were contentious. The report of the High-Level Panel, for example, argued against a target for addressing in-country income inequality on the grounds that "countries differ widely both in their view of what levels of income inequality are acceptable and in the strategies they adopt to reduce it." 9 Others argued that a target for in-country income inequality was unnecessary, given the strong instrumental importance of reducing income inequality toward the achievement of targets for eradicating income poverty, measured by the $\$ 1$-a-day international poverty line; while still others pointed to the limitations of income as a measure of wellbeing. ${ }^{10}$

Finally, while the importance of addressing inequalities between countries was widely recognized, this was more often addressed indirectly, through proposed goals and targets relating to global governance, which if met might be expected to reduce international inequality: for instance, by achieving the 0.7 percent target for official development assistance as a share of gross national product, and by substantially reducing trade-distorting agricultural subsidies. ${ }^{11}$

The SDGs were adopted by the UN General Assembly in September 2015, following the final report of the Open Working Group on the Sustainable Development Goals, published in August 2014. There are 17 goals, accompanied by 169 targets; the latter are described as "global and aspirational," with the expectation that each government will set its own national targets, "guided by the global level of ambition but taking into account national circumstances." ${ }^{2}$ At the time of writing, the final list of indicators to be used to monitor progress against each target was still under review, although general agreement has been reached on 159 indicators, referred to as "green" indicators. ${ }^{13}$ 
In total, around 50 of the SDG targets refer to individual outcomes, and of these around two-thirds are universal or zero-based. Examples include eradicating extreme poverty (Target 1.1); ending hunger (2.1); ending preventable deaths of children under five (3.2); ensuring that all girls and boys complete primary and secondary education (4.1); ending all forms of discrimination against all women and girls (5.1); and achieving universal access to safe and affordable drinking water (6.1). By way of comparison, only a third of the MDG targets referring to individual outcomes were framed in this way. This reflects earlier proposals made in the buildup to 2015, and helps address the perverse incentives problem that characterized the MDGs.

Nevertheless, around a third of the SDG targets referring to individual outcomes are not universal or zero-based, and do not therefore have to be met by all groups within a population. Examples include reducing by half the proportion of people living in poverty according to national definitions (1.2); reducing the maternal mortality ratio to less than 70 per 100,000 live births (3.1); and ensuring that a "substantial proportion" of adults achieve literacy and numeracy (4.6). Presumably, national governments will be expected to develop their own national targets in these cases, guided by, but not necessarily equal to, the agreed global targets. However, it remains to be seen whether these national targets will need to be met for subgroups within each country, as well as at the national level. If not, the problem of perverse incentives will continue to apply.

Notably, the Sustainable Development Goals contain a stand-alone goal for addressing inequality. This is Goal 10, framed as "Reduce inequality within and among countries." The goal has 10 targets, which address different dimensions of inequality-including, but not restricted to, income inequality — and cover national as well as international inequality (see list below). The next sections provide a more detailed analysis of this goal, focusing first on Target 10.1 . 
SDG 10: Reduce inequality within and among countries

\begin{tabular}{|c|c|}
\hline 10.1 & $\begin{array}{l}\text { By 2030, progressively achieve and sustain income growth of the bottom } 40 \text { percent } \\
\text { of the population at a rate higher than the national average. }\end{array}$ \\
\hline 10.2 & $\begin{array}{l}\text { By } 2030, \text { empower and promote the social, economic, and political inclusion of all, } \\
\text { irrespective of age, sex, disability, race, ethnicity, origin, religion, or economic or } \\
\text { other status. }\end{array}$ \\
\hline 10.3 & $\begin{array}{l}\text { Ensure equal opportunity and reduce inequalities of outcome, including by } \\
\text { eliminating discriminatory laws, policies, and practices and promoting appropriate } \\
\text { legislation, policies, and action in this regard. }\end{array}$ \\
\hline 10.4 & $\begin{array}{l}\text { Adopt policies, especially fiscal, wage, and social protection policies, and } \\
\text { progressively achieve greater equality. }\end{array}$ \\
\hline 10.5 & $\begin{array}{l}\text { Improve the regulation and monitoring of global financial markets and institutions } \\
\text { and strengthen the implementation of such regulations. }\end{array}$ \\
\hline 10.6 & $\begin{array}{l}\text { Ensure enhanced representation and voice for developing countries in decision- } \\
\text { making in global international economic and financial institutions in order to deliver } \\
\text { more effective, credible, accountable, and legitimate institutions. }\end{array}$ \\
\hline 10.7 & $\begin{array}{l}\text { Facilitate orderly, safe, regular, and responsible migration and mobility of people, } \\
\text { including through the implementation of planned and well-managed migration } \\
\text { policies. }\end{array}$ \\
\hline $10 . \mathrm{a}$ & $\begin{array}{l}\text { Implement the principle of special and differential treatment for developing } \\
\text { countries, in particular least developed countries, in accordance with World Trade } \\
\text { Organization agreements. }\end{array}$ \\
\hline $10 . \mathrm{b}$ & $\begin{array}{l}\text { Encourage official development assistance and financial flows, including foreign } \\
\text { direct investment, to States where the need is greatest, in particular least developed }\end{array}$ \\
\hline
\end{tabular}




\begin{tabular}{|c|c|}
\hline & $\begin{array}{l}\text { countries, African countries, small island developing States, and landlocked } \\
\text { developing countries, in accordance with their national plans and programmes. }\end{array}$ \\
\hline 10.c & $\begin{array}{l}\text { By 2030, reduce to less than } 3 \text { percent the transaction costs of migrant remittances } \\
\text { and eliminate remittance corridors with costs higher than } 5 \text { percent. }\end{array}$ \\
\hline
\end{tabular}

Source: UN document A/RES/70/1.

\section{Goal 10, Target 1: Addressing Income Inequality?}

Target 10.1 relates to income inequality. This is perhaps not immediately obvious, since the wording refers to income growth rather than income inequality per se. However, if the incomes of the bottom 40 percent of the population grow by more than the national average, their share of national income will rise. This is essentially a matter of accounting. The share of income received by the poorest 40 percent is in turn one recognized way of measuring income inequality, so an equivalent way of phrasing this target would be: By 2030, progressively achieve and sustain a reduction in income inequality, as measured by the share of the bottom 40 percent of the population in national income, alongside economic growth.

Target 10.1, therefore, already comes with a "built-in" inequality indicator: the share of the poorest 40 percent in national income. This implies a certain amount of continuity with the MDGs, since the share of the poorest 20 percent in national income was one of the three indicators specified for MDG Target 1.A-halving the proportion of people living on less than \$1-a-day. That indicator received relatively little attention in MDG monitoring exercises, however, and became somewhat redundant, because MDG Target 1.A already came with its own "built-in" indicator, namely the proportion of people living on less than $\$ 1$-a-day. Target 10.1 ensures that trends in the share of the poorest 40 percent in national income cannot be ignored in the same way under the SDGs. 
There was a lot of discussion in the lead-up to the post-2015 framework on the pros and cons of different measures of income inequality. One perceived advantage of measures based on shares of national income, such as the share of the bottom 40 percent of the population or the Palma index, is that they are relatively easily understood, at least in comparison with more technical measures such as the Gini coefficient. ${ }^{14}$ A drawback, however, is that income shares do not convey information about the entire income distribution. For example, a rise in inequality between the richest 10 percent and the middle 20 percent of the population may have no impact on the income share received by the bottom 40 percent of the population.

More generally, the choice of inequality measures is a normative one, and for that reason it is not obvious that all countries should use the same indicator. An alternative would have been to phrase Target 10.1 more generally_for example, By 2030, progressively achieve and sustain a reduction in income inequality, alongside economic growth — and then specify a range of different inequality indicators. This would give countries more flexibility in terms of deciding which particular indicator to use. A parallel here would be MDG Target 1.C, which called for halving the proportion of people who suffer from hunger by 2015 , and then gave two different indicators for measuring hunger.

Additionally, Target 10.1 does not specify an "acceptable" level of inequality to be aimed for. It does not, for instance, require that the share of the bottom 40 percent of the population be at least $\mathrm{X}$ percent of national income, or at least as large as the share of the richest 10 percent of the population. Instead, Target 10.1 requires only that the share of the bottom 40 percent rises over time. For this reason, Target 10.1 might best be regarded as a minimum requirement that all countries are expected to meet, with each government being expected to set its own more specific targets - in particular, the actual reduction in inequality to be achieved by 2030 . The implicit assumption would then be that current levels of income inequality are excessive in all countries of the world, although targets for the reduction of inequality may 
vary from one country to another, depending on how far each country is from an acceptable level of inequality. This makes sense up to a point, although some countries might argue that they have already achieved an acceptable level of inequality, and are exempt from the minimum global requirement. Would such arguments be accepted? And if not, why not? When it comes to monitoring this target, it might therefore be difficult to avoid specifying what an acceptable level of income inequality is, and when income inequality becomes excessive.

The phrase "progressively achieve and sustain" in Target 10.1 is also somewhat problematic. Clearly, the idea of progressive achievement would make sense if the target was to reach a certain acceptable level of income inequality, which for some countries could take some time. But since Target 10.1 requires only that income inequality be falling over time, it is less clear why this needs to be achieved progressively. Strictly speaking, the target could be met by gradually reducing the amount by which income inequality rises over time, as long as inequality is falling in the years immediately prior to 2030. There is nothing to require specifically that the level of income inequality in 2030 be lower than in 2015 .

\section{Goal 10, Target 3: Ensuring Equal Opportunity?}

Target 10.3 refers to the common distinction made between equality of opportunity and equality of outcome, asking states to work toward both. The requirement to reduce inequalities of outcome overlaps to some extent with Target 10.1, since income is clearly one important type of outcome. However, Target 10.3 could encompass inequalities in other important life outcomes, such as educational attainment or health status. This could be clarified with the development of indicators for this target — for example, by specifying one indicator for each type of non-income inequality that is considered important. This part of Target 10.3 would then constitute an important complement to Target 10.1, given the recognized limitations of relying solely on income as a measure of a person's wellbeing or achievements. 
The requirement in Target 10.3 to ensure equal opportunity is more problematic, since there are different understandings of what this term means. The "conventional" definition requires that people's outcomes in life should be determined only by their efforts and talents, rather than by predetermined circumstances such as their social or family background, gender, or ethnicity. ${ }^{15}$ But a "minimal" definition requires only that "a person's race or gender or religion should not be allowed to affect their chances of being selected for a job, of getting a good education, and so on." 16 There is also a more "radical" definition that requires that a person's prospects be influenced neither by one's social position nor by one's natural talents. ${ }^{17}$

If the conventional definition is accepted, then the next question is one of measurement. What indicators might be used to measure equality of opportunity? One possible approach is set out by Francisco Ferreira and Jérémie Gignoux. ${ }^{18}$ To illustrate, imagine a household survey that contains information for each individual on a particular outcome (for instance, income) and on four predetermined circumstances (such as gender, ethnicity, disability status, and parental wealth). Let us also assume that for each circumstance there are two different categories, such as men and women for gender, rich and poor for parental wealth, and so on. The population can therefore be divided into sixteen subgroups, each of which contains individuals with the same observed set of circumstances (for example, white males from rich backgrounds without a disability, white males from poor backgrounds without a disability, and so on). The total amount of income inequality across all individuals in society can then be broken down into the amount of inequality within each of these groups (the "within-group" component) and the amount of inequality between the average income of each group (the "between-group" component). The size of the between-group component of overall inequality can then be used as a measure of inequality of opportunity, on the grounds that differences in average incomes between subgroups in all likelihood reflect the effect of discrimination and/or structural disadvantage — as opposed to differences in choices, values, or aspirations. 
Although the approach set out by Ferreira and Gignoux refers to income inequality, it could also be applied to inequality in other outcomes, such as health status or educational attainment, where inequalities between groups defined by predetermined circumstances have also been shown to be substantial. Among young adults in Nigeria, for example, average years of schooling vary significantly according to gender, location, household wealth, and ethnicity. Poor rural Hausa young women have less than half a year of schooling on average, while rich young men in urban areas have an average of over ten years. ${ }^{19}$ If this approach to measuring (in)equality of opportunity were utilized for Target 10.3, the implication would be that countries would need to eliminate inequalities in income between groups defined by predetermined circumstances by 2030 . This would be a challenging task for many countries. For a sample of six countries in Latin America, for example, Ferreira and Gignoux find that inequality of opportunity accounts for between 25 and 51 percent of overall income inequality. ${ }^{20}$ If this is considered too challenging, the alternative would be for countries to specify target reductions in inequality of opportunity to be achieved by 2030 consistent with national circumstances.

As it currently stands, however, only one indicator has been proposed for Target 10.3: the percentage of the population having felt discriminated against or harassed on grounds prohibited under international human rights law. Although this is clearly a very important metric, it is difficult to believe that it can by itself capture the full sense of what is meant by the term "equality of opportunity" - even a "minimal" definition of the term. As with Target 10.1, a greater range of indicators is arguably called for.

\section{Goal 10, Targets 5-7 and a-c: Addressing International Inequality?}

There are no targets under Goal 10 to reduce international inequality per se; for example, there is no target to reduce the global Palma index. Instead, there are targets for steps or actions that 
might be expected to reduce international inequality: in particular, improving the regulation of global financial markets (10.5); ensuring the enhanced representation of developing countries in international economic and financial institutions (10.6); facilitating orderly, safe, regular, and responsible migration (10.7); implementing the principle of special and differential treatment for developing countries (10.a); encouraging official development assistance and financial flows (10.b); and reducing the transaction costs of migrant remittances (10.c).

The lack of a specific target for reducing international (or global) income inequality is perhaps a surprise, given that around two-thirds of income inequality at the global level is due to inequality between countries, as opposed to inequality within countries. ${ }^{21}$ It is also surprising given the argument that targets should focus on the ends, rather than the means, of development. ${ }^{22}$ However, it could be argued that international income inequality is too far beyond the control of policymakers to constitute a valid target. Any target would lack "action orientation," since the extent of progress toward the target would in all likelihood be due to factors outside policy control. For example, the simple fact that some of the fastest growing countries in the world have very large populations — notably China and India— has exerted a powerful narrowing force on international income inequality in recent decades. ${ }^{23}$ The extent of this correlation - between rates of economic growth and population size - will continue to have important implications for international and global inequality in future decades, but it is not something over which policymakers can have much control.

There are therefore grounds for framing targets in this area in terms of actions that the international community should take that are considered to be conducive to the reduction of international inequality, rather than in terms of the reduction of international inequality per se. Nevertheless, this leads to overlap and a certain amount of repetition between the targets relating to international inequality in Goal 10 and the targets relating to global governance in Goal 17. For example, the Goal 10 target to encourage official development assistance overlaps 
with Goal 17, Target 2, which calls more specifically for "developed countries to implement fully their ODA commitments, including to provide 0.7 per cent of gross national income in official development assistance to developing countries, of which 0.15 to 0.20 percent should be provided to least developed countries." Similarly, the Goal 10 target to implement the principle of special and differential treatment (10.a) overlaps with Goal 17, Target 12, which calls more specifically for the "timely implementation of duty-free and quota-free market access on a lasting basis for all least developed countries, consistent with World Trade Organization decisions, including by ensuring that preferential rules of origin applicable to imports from least developed countries are transparent and simple, and contribute to facilitating market access."

If anything, the action targets relating to international inequality in Goal 10 are weaker than their counterparts in Goal 17, which calls into question their value-added in the overall SDG framework. There is also an absence of quantification for these targets. They do not specify the extent of change sought in any particular indicator; they are instead framed in more qualitative terms: "improving," "encouraging," "implementing," "facilitating," and so on. They also do not specify a target deadline, so it is unclear whether the actions referred to are to be achieved immediately or by 2030 . This lack of specificity potentially undermines the role of these targets as incentivizing and accountability devices.

\section{Conclusion}

The Sustainable Development Goals represent a potential improvement over the Millennium Development Goals in their treatment of inequality, notably through the greater emphasis on zero-based, universal targets, and also through the inclusion of a separate, stand-alone goal for equality (Goal 10, Reduce Inequality, Within and Among Countries). Will SDG 10 be a success? It has been argued that the MDGs were a success not because the targets were all 
achieved by 2015 - while some were met (for example, reducing extreme poverty by half), others were not (for example, universal primary education)—but because they caused policymakers in governments and international agencies to give greater priority to policies that promote basic human outcomes such as freedom from hunger, education for all, access to clean drinking water, and so on. ${ }^{24}$ Will SDG 10 have a similar impact, increasing the priority given by governments and other agencies to the reduction of inequality, both within and between countries?

At this stage, a number of questions remain unresolved about SDG 10 that have the potential to undermine its impact. One relates to indicators, and whether it makes sense to specify a single indicator of income inequality—such as the share of national income received by the poorest 40 percent of the population — rather than allowing for a wider range of measures to be used in monitoring progress, such as the Gini coefficient or Palma index. Another question is whether, and if so, how, the minimum global requirement embodied in Target 10.1 for countries to reduce income inequality should be translated into more specific, quantitative targets at the national level. A third is how the key concept of "equal opportunity" featured in Target 10.3 is to be conceptualized, and whether the single indicator currently proposed for this target sufficiently captures the full sense of the term. Finally, there is the issue of potential overlap between the action-oriented goals relating to international inequality in Goal 10 and similar targets relating to global governance in Goal 17. Further discussion on these questions is required if the targets embodied in Goal 10 are to play their full role as incentivizing and accountability devices. 


\section{NOTES}

${ }^{1}$ See David Hulme, "The Millennium Development Goals (MDGs): A Short History of the World's Biggest Promise,” BWPI Working Paper No. 100 (2009), Institute for Development Policy and Management, University of Manchester.

${ }^{2}$ See Naila Kabeer, "Can the MDGs Provide a Pathway to Social Justice? The Challenge of Intersecting Inequalities,” Institute of Development Studies (IDS)/United Nations Development Programme (UNDP), New York, 2010; Malcolm Langford, “A Poverty of Rights: Six Ways to Fix the MDGs," IDS Bulletin 41, no. 1 (2010), pp. 83-89; and Catarina de Albuquerque, United Nations Special Rapporteur on the human right to safe drinking water and sanitation, "The Future Is Now: Eliminating Inequalities in Sanitation, Water and Hygiene" (2012).

${ }^{3}$ See Sakiko Fukuda-Parr, "Poverty and Inequality - Challenges in the Era of Globalization," in A. Mark-Jungkvist and S. Ask, eds., The Adventure of Peace: Dag Hammarskjöld and the Future of the United Nations (New York: Palgrave MacMillan, 2006); Jan Vandemoortele, "The MDG Conundrum: Meeting the Targets without Missing the Point," Development Policy Review 27, no. 4 (2009), pp. 355-71; Jan Vandemoortele, "The MDG Story: Intention Denied," Development and Change 42, no. 1 (2011), pp. 1-21; Jan Vandemoortele and Enrique Delamonica, “Taking the MDGs Beyond 2015: Hasten Slowly,” IDS Bulletin 41, no. 1 (2010), pp 60-69; and United Nations Research Institute for Social Development, Flagship Report 2010: Combating Poverty and Inequality (Geneva: UNRISD, 2010).

${ }^{4}$ High-Level Panel of Eminent Persons on the Post-2015 Development Agenda, A New Global Partnership: Eradicate Poverty and Transform Economies through Sustainable Development, May 30, 2013. Lower secondary education corresponds to Level 2 of the International Standard Classification of Education (ISCED). This typically consists of the first three years of schooling after the completion of primary education.

${ }^{5}$ See United Nations System Task Team on the Post-2015 Development Agenda, Addressing Inequalities: The Heart of the Post-2015 Agenda and the Future We Want for All, May 2012; High-Level Panel, A New Global Partnership.

${ }^{6}$ United Nations Sustainable Development Solutions Network, An Action Agenda for Sustainable Development: Report for the UN Secretary-General, June 6, 2013, p. 29.

${ }^{7}$ See Save the Children, Born Equal: How Reducing Inequality Could Give Our Children a Better Future (London: Save the Children, 2012); Kevin Watkins, "Inequality as a Barrier to Human Development," Kapuscinski Development Lecture, Stockholm School of Economics, 
March 5, 2013; Lars Engberg-Pedersen, "Development Goals Post 2015: Reduce Inequality," Danish Institute for International Studies, Copenhagen, 2013; Alex Cobham and Andy Sumner, "Putting the Gini Back in the Bottle? 'The Palma' as a Policy-Relevant Measure of Inequality" (2013); UNRISD, Inequalities and the Post-2015 Development Agenda, Research and Policy Brief No. 15, October 2012; and Michael Doyle and Joseph Stiglitz, "Eliminating Extreme Inequality: A Sustainable Development Goal, 2015-2030," Ethics and International Affairs 28, no. 1 (2014).

${ }^{8}$ See Engberg-Pedersen, “Development Goals Post 2015: Reduce Inequality,” and Charles Gore, "Reducing International Income Inequality,” Broker, January 29, 2013.

${ }^{9}$ High-Level Panel, A New Global Partnership, p. 16.

${ }^{10}$ See Stephan Klasen, “No, We Don’t Need an MDG for Inequality,” Broker, December 17, 2012; see also Albuquerque, "The Future is Now"; Claire Melamed, "Putting Inequality in the Post-2015 Picture," Overseas Development Institute, London, March 2012; and the United Nations System Task Team on the Post-2015 Development Agenda, Addressing Inequalities.

${ }^{11}$ High-Level Panel, A New Global Partnership.

${ }^{12}$ Resolution Adopted by the United Nations General Assembly on September 25, 2015, “Transforming Our World: The 2030 Agenda for Sustainable Development," UN document A/RES/70/1, p. 13. See also the Report of the United Nations Open Working Group of the General Assembly on Sustainable Development Goals, Open Working Group Proposal for Sustainable Development Goals, UN document A/68/970, August 12, 2014, p. 9.

${ }^{13}$ United Nations Inter-Agency Expert Group on SDG Indicators (IAEG-SDG), "Results of the List of Indicators Reviewed at the Second IAEG-SDG Meeting (October 26-28, 2015)," November 2, 2015.

${ }^{14}$ United Nations System Task Team on the Post-2015 UN Development Agenda, "Statistics and Indicators for the Post-2015 Development Agenda," New York, July 2013; Cobham and Sumner, "Putting the Gini Back in the Bottle?"

15 John Roemer, Equality of Opportunity (Cambridge: Harvard University Press, 1998); Adam Swift, Political Philosophy: A Beginner's Guide for Students and Politicians (Cambridge: Polity Press, 2006); David Miller, "What is Social Justice?” in Nick Pearce and Will Paxton, eds., Social Justice: Building a Fairer Britain (London: Politico's Publishing, 2005); and the World Bank, World Development Report 2006: Equity and Development (New York: Oxford University Press for the World Bank, 2005).

${ }^{16}$ Swift, Political Philosophy, p. 99. 
${ }^{17}$ Ibid., p. 101.

${ }^{18}$ Francisco Ferreira and Jérémie Gignoux, "The Measurement of Inequality of Opportunity: Theory and an Application to Latin America," Review of Income and Wealth 57, no. 4 (2011), pp. 622-57.

${ }^{19}$ See Watkins, "Inequality as a Barrier to Human Development."

${ }^{20}$ Ferreira and Gignoux, "The Measurement of Inequality of Opportunity."

${ }^{21}$ See Branko Milanovic, Worlds Apart: Measuring International and Global Inequality (Princeton: Princeton University Press, 2005); and Branko Milanovic, The Haves and the Have-Nots: A Brief and Idiosyncratic History of Global Inequality (New York: Basic Books, 2011).

${ }^{22}$ Office of the United Nations High Commissioner for Human Rights (OHCHR) and the Center for Economic and Social Rights (CESR), Who Will Be Accountable? Human Rights and the Post-2015 Development Agenda, New York and Geneva, 2013.

${ }^{23}$ See Milanovic, Worlds Apart.

${ }^{24}$ Olav Kjorven, "Why_-So Far-the Millennium Development Goals Have Been a Success," UNDP, Bureau for Development Policy, New York, August 23, 2011. 